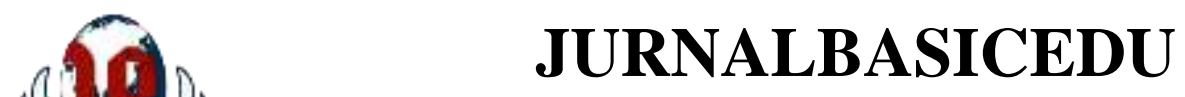

Volume 6 Nomor 1 Tahun 2022 Halaman 386 - 393

Research \& Learningin Elementary Education https://jbasic.org/index.php/basicedu

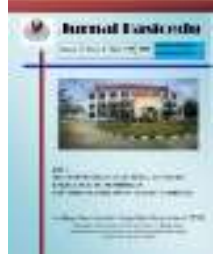

\title{
Desain Aplikasi "SAPA" Berbasis Computer-Mediated Communication (CMC) Untuk Efektivitas Komunikasi Mahasiswa Tunarungu
}

\author{
Joko Slamet Saputro $^{1 凶}$, Fadjri Kirana Anggarani ${ }^{2}$, Arsy Anggrellangi ${ }^{3}$ \\ Teknik Elektro, Universitas Sebelas Maret, Indonesia ${ }^{1}$, Psikologi, Universitas Sebelas Maret, Indonesia ${ }^{2}$, \\ Pendidikan Luar Biasa, Universitas Sebelas Maret, Indonesia ${ }^{3}$

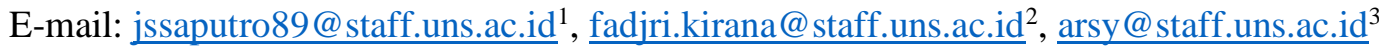

\begin{abstract}
Abstrak
Komunikasi antara penyandang disabilitas dengan orang normal masih sulit bahkan dengan adanya bahasa isyarat. Penelitian ini bertujuan untuk pengembangan aplikasi "SAPA" berbasis Computer-Mediated Communication (CMC) untuk efektivitas komunikasi antara tunarungu - tunanetra. Metode penelitian yang digunakan adalah penelitian pengembangan Research and Development ( $\mathrm{R} \& \mathrm{D})$. Penelitian pengembangan adalah model pengembangan sebuah produk dari mulai perancangan, validasi, pengujian produk, dan desiminasi produk secara luas. Tahapan pengembangan aplikasi pada penelitian ini meliputi; stdudi pendahuluan, perancangan produk, validasi produk, perbaikan produk, uji coba produk dan penyempurnaan produk final. Hasil pengujian aplikasi yang dilakukan didapatkan analisis yang berisi ouput Paired Samples Test menunjukkan nilai Sig.(2-tailed) adalah sebesar $0.000<0.05$, maka $\mathrm{H}_{0}$ ditolak dan $\mathrm{H}_{\mathrm{a}}$ diterima. Dapat ditarik kesimpulan bahwa, ada perbedaan rata - rata antara komunikasi mahasiswa pada saat sebelum dan sesudah menggunakan aplikasi "SAPA" yang artinya ada pengaruh pada penggunaan aplikasi "SAPA" untuk mengatasi masalah komunikasi mahasiswa tunarungu, tunanetra, non-disabilitas, dan dosen pengampu mata kuliah, sehingga tercipta komunikasi yang efektif dalam perkuliahan.
\end{abstract}

Kata Kunci: Computer-Mediated Communication (CMC), komunikasi, tunarungu

\begin{abstract}
Communication between persons with disabilities and normal people is still difficult even with the presence of sign language. This study aims to develop the application "SAPA" based on Computer-Mediated Communication (CMC) for the effectiveness of communication between the deaf - blind. The research method used is research and development research and development $(R \& D)$. Research and development is a model for developing a product from designing, validating, testing products, and broadly distributing products. The stages of application development in this research include; preliminary study, product design, product validation, product improvement, product testing and final product refinement. The results of the application testing carried out obtained an analysis containing the Paired Samples Test output showing the value of Sig. (2-tailed) was $0.000<0.05$, then $H_{0}$ was rejected and $H_{a}$ was accepted. It can be concluded that, there is an average difference between student communication before and after using the "SAPA" application, which means that there is an influence on the use of the "SAPA" application to overcome the communication problems of students who are deaf, blind, non-disabled, and lectures, so as to create effective communication in lectures.
\end{abstract}

Keywords: Computer-Mediated Communication (CMC), communication, deaf.

Copyright (c) 2022 Joko Slamet Saputro, Fadjri Kirana Anggarani, Arsy Anggrellangi

$\triangle$ Corresponding author :

Email : jssaputro89@staff.uns.ac.id

DOI : https://doi.org/10.31004/basicedu.v6i1.1931 

Anggrellangi

DOI: https://doi.org/10.31004/basicedu.v6i1.1931

\section{PENDAHULUAN}

Komunikasi merupakan prasyarat hidup bagi manusia untuk mencapai kehidupan yang bermakna. Komunikasi yang hilang tidak akan terjadi interaksi antar manusia, baik secara individu, kelompok, maupun organisasi tidak mungkin terjadi (Tukimin et al., 2019). Dua orang dikatakan berinteraksi bila masing-masing melakukan aksi dan reaksi. Sebagai makhluk sosial, setiap manusia tidak bisa lepas dari tindakan komunikasi, yaitu tindakan menyampaikan dan menerima pesan dari dan kepada orang lain (Tukimin et al., 2019). Tindakan komunikasi ini berlanjut sepanjang proses kehidupan. Proses tersebut terjadi dalam berbagai konteks fisik, psikologis, dan sosial. Komunikasi menjadi penting karena fungsi yang dapat dirasakan oleh pelaku komunikasi. Komunikasi dapat digunakan orang menyampaikan gagasan atas pikiran dan perasaan hati nuraninya kepada orang lain baik secara langsung maupun tidak langsung (Abdallah \& Fayyoumi, 2016; Tukimin et al., 2019). Dapat membuat dirinya tidak merasa terasing atau terisolasi dari lingkungan sekitarnya dan mudah untuk memenuhi kebutuhan hidupnya (Alnfiai \& Sampali, 2017; Hersh, 2013).

Komunikasi sosial adalah salah satu pilar terpenting yang didasari oleh masyarakat kita (Abdallah \& Fayyoumi, 2016). Bahasa adalah satu-satunya cara kunci untuk berkomunikasi dan berinteraksi satu sama lain secara verbal atau non-verbal (Abdallah \& Fayyoumi, 2016). Difabel adalah anggota masyarakat ini dan memiliki hak untuk menikmati komunikasi dengan lingkungan eksternal dengan cara yang mudah dan profesional. Tunarungu sering disebut Tuli berbeda dari disabilitas lainnya, karena adanya bahasa lain yang mengimbangi bahasa verbal atau lisan dan dikenal sebagai bahasa isyarat (Zaenudin, 2017). Dalam masyarakat dapat mendefinisikan bahasa isyarat adalah bahasa yang digunakan oleh orang tuli untuk berkomunikasi satu sama lain dan dengan orang lain. Terlepas dari adanya bahasa lain yang mengkompensasi bahasa verbal (Abdallah \& Fayyoumi, 2016). Komunikasi antara penyandang disabilitas dengan orang normal masih sulit bahkan dengan adanya bahasa isyarat (Hersh, 2013). Ini karena kesalahpahaman atau miskonsepsi yang umum terjadi di antara orang-orang (Ehn et al., 2019).

Hal ini juga terjadi ketika tunarungu dan tunanetra bertemu maka tidak akan terjadi komunikasi yang efektif. Tunarungu yang masih bisa melihat secara visual tetapi tidak bisa berbicara, mendengar dan mengandalkan Bahasa isyarat dan tulis (Chee et al., 2016). Perbandingan terbalik dengan tunanetra yang tidak bisa melihat akan tetapi dapat bisa mendengar dan berbicara dengan lancar. Perbedaan tersebut menyebabkan kebingungan tunarungu ketika menyapa tunantera, sebaliknya tunanetra tidak tahu ada temannya tunarungu di dekatnya karena tidak mengajaknya berbicara secara oral (Caporusso et al., 2014). Adanya interaksi antara tunarungu dengan tunanetra diperlukan dalam rangka silaturahim dan jual beli, namun kedua individu tersebut tidak dapat berkomunikasi dengan baik dikarenakan kendala pesan yang tidak dapat diterima atau disampaikan melalui alat komunikasi yang ada (Tukimin et al., 2019).

Komunikasi adalah urat nadi bersosialisasi, dimana siklus komunikasi hanya efektif dan selesai ketika penerima memahami pesan serta niat pengirim (Destiny et al., 2017). Dengan kemajuan teknologi informasi dan komunikasi, oleh karena itu perlu dibuat suatu bantu komunikasi yang dapat menghubungkan kedua individu tersebut, alat bantu komunikasi yang dirancang dapat mengakomodasi kebutuhan tersebut (Maciver et al., 2019; Monteiro et al., 2013). Pemanfaatkan teknologi komunikasi yang meningkat pemerataan akses komunikasi secara berkelanjutan dan mudah (Chee et al., 2016). Teknologi komunikasi menciptakan kondisi yang meningkatkan akses langsung ke bahasa dan literasi (Garberoglio et al., 2015). Membantu komunikasi antara dua individu tunarungu - tunanetra dengan teknologi saat perlu dikembangan menggunakan ComputerMediated Communication (CMC) (Landicho, 2016). CMC merupakan komunikasi yang terjadi antara dua orang atau lebih melalui komputer sebagai mediumnya (Akhsan, 2020).

CMC sudah banyak digunakan dalam interaksi antar manusia (Gambo \& Özad, 2020). Temuan menawarkan bukti empiris yang mendukung kegunaan CMC untuk kegiatan sosial bersama, dukungan, dan 

Anggrellangi

DOI: https://doi.org/10.31004/basicedu.v6i1.1931

mendorong lebih banyak interaksi antara individu baik individu non-disabilitas maupun tunarungu dan tunanetra (Eden \& Heiman, 2011). Computer-Mediated Communication untuk mengurangi isolasi sosial yang dialami oleh banyak individu tunarungu dan tunantera ketika bertemu di lingkungan masyarakat (Bishop et al., 2000). CMC memudahkan berinteraksi dengan berbagi bentuk cara berkomunikasi baik online maupun secara langsung, termasuk mereka yang tunarungu dan tunanetra remaja maupun anak - anak (Ramadhana \& Yusanto, 2020). Berbagai penggunaan CMC mengubah sifat interaksi sosial dan hubungan manusia di kalangan remaja tunarungu dan tunanetra (Durkin et al., 2010). CMC dapat digunakan media yang adaptif untuk mengatasi masalah Bahasa dalam berkomunikasi yang berbasis sistem android (Bitman \& John, 2019; Skilton et al., 2018). Penggunaan sistem android dalam CMC dimaksudkan untuk memudahkan komunikasi dengan aplikasi yang dapat dibantu dengan sistem yang telah disiapkan sesuai dengan kebutuhan tunarungu dan tunanetra (Abdallah \& Fayyoumi, 2016; Skilton et al., 2018).

Berdasarkan latar belakang yang telah diuraikan penelitian ini bertujuan untuk pengembangan aplikasi "SAPA" berbasis Computer-Mediated Communication (CMC) untuk efektivitas komunikasi antara tunarungu - tunanetra. Dalam pengembangan aplikasi ini disesuaikan dua arah dengan keunggulan tunarungu dalam visual atau penglihatan. Komunikasi tunarungu dengan sistem android dengan bahasa isyarat dan chat yang akan ditransformasikan ke suara ke tunanetra yang bisa mendengar (Buvaneswari et al., 2020). Komunikasi tunanetra ke tunarungu sistem android menyiapakan penangkap suara yang akan ditransformasikan ke dalam teks ataupun avatar Bahasa isyarat. Mahasiswa non-disabilitas dapat menggunkan aplikasi dengan mengubah suara menjadi bahasa isyarat dan teks. Aplikasi "SAPA" dikembangkan dengan prinsip desain universal untuk menghilangkan stigma sosial yang terkait dengan penggunaan teknologi spesialis, mengurangi biaya, serta mempromosikan rasa inklusi mereka (Okonji, 2018).

\section{METODE PENELITIAN}

Penelitian ini bertujuan untuk pengembangan Aplikasi "SAPA" Berbasis Computer-Mediated Communication (CMC). Berdasarkan tujuan penelitian tersebut, jenis penelitian yang digunakan adalah penelitian pengembangan Research and Development ( $\mathrm{R} \& \mathrm{D})$. Penelitian pengembangan adalah model pengembangan sebuah produk dari mulai perancangan, validasi, pengujian produk, dan desiminasi produk secara luas (Borg \& Gall, 2003). Tahapan pengembangan aplikasi pada penelitian ini meliputi; stdudi pendahuluan, perancangan produk, validasi produk, perbaikan produk, uji coba produk dan penyempurnaan produk final. Studi pendahuluan, observasi dilakukan dengan cara mengamati objek pengamatan secara langsung, pengamatan secara langsung akan dilakukan pada situasi perkuliahan di kampus dengan hambatan pendengaran atau tunarungu. Pengamatan dimaksudkan untuk mengetahui hambatan yang dialami mahasiswa hambatan pendengaran atau tunarungu dalam berkomunikasi di perkuliahan dengan mahasiswa lain yang tunanetra dan non-disabilitas serta dengan dosen pengampu mata kuliah. Pada studi pendahuluan sekaligus untuk mengidentifikasikan permasalahan yang ditemukan serta mengajukan solusinya.

Perancangan produk, pada tahap ini disesuaikan dengan hasil studi pendahuluan. Dimulai dari tahap identifikasi permasalahan untuk digunakan sebagai dasar pengembangan aplikasi SAPA. Produk yang akan dirancang disesuaikan dengan kebutuhan di lapangan, sehingga dalam perencangan aplikasi SAPA dapat mengakomodasi kebutuhan tunarungu-tunanetra dan non-disabilitas serta dosen dalam hal komunikasi di perkuliahan. Aplikasi SAPA menggunakan model avatar 3D dalam merepresentasikan bahasa isyarat dan menggunakan algoritma cerdas speech recognition yang dapat mengolah bentuk suara menjadi bentuk lain. Aplikasi SAPA didesain dengan simple dan user-friendly, sehingga memberikan pengoperasian yang lebih mudah dan tepat guna. Validasi produk, tahap ini melibatkan ahli yang sesuai dengan bidang keahlian yang dibutuhkan dalam penegmbangan aplikasi "SAPA". Pengembangan aplikasi ini melibatkan lima validasi ahli 
antara lain; ahli Pendidikan Luar Biasa, ahli Teknologi Pendidikan, ahli Teknologi Informasi, ahli Bahasa Isyarat, dan ahli desain grafis aplikasi serta 11 praktisi (guru, Juru Bahasa Isyarat, GERGATIN). Para validator menilai kelayakan produk yang dihasilkan sebelum dilakukan pengujian di lapangan. Saran - saran yang diberikan validator ahli akan menjadi bahan perbaikan dan penyempurnaan aplikasi "SAPA" agar siap digunakan dalam pengujian dan diseminasi ke masyarakat.

Perbaikan produk, didasarkan pada saran - saran yang diberikan validator ahli sebelumnya. Produk direvisi untuk perbaikan dan penyempurnaan aplikasi "SAPA", sehingga siap dilakukan uji coba di lapangan. Perbaikan melihat sistem sudah dapat berfungsi denggan baik sesuai tujuan pengembangan. Uji coba produk, engujian aplikasi "SAPA" dilakukan peneliti untuk pengujian langsung di lapangan. Uji coba melibatkan mahasiswa tunarungu, tunantera, non- disabilitas, dan dosen pengampu mata kuliah. Dalam tahap pengujian ini untuk melihat fungsi dari fitur - fitur aplikasi "SAPA" yang dikembangkan peneliti. Peneliti ingin mendapatkan respon secara langsung dari caln pengguna aplikasi dan melihat efektifitas komunikasi yang terbangun melalui aplikasi "SAPA". Penyempurnaan produk final, tahpan terkahir yang dilakukan dengan memperhatikan feedback yang diberikan oleh tester. Penyempurnaan dilakukan dari sisi fungsionalitas fitur fitur produk agar produk ketika sudah digunakan masyarakat dapat bekerja secara optimal dan wearable. Pada tahap akhir penyempuranaan produk adalah melihat sensitifitas suara ayang diterjemahkan dengan aplikasi "SAPA" dapat berjalan dengan baik dan dapat merangkai kata atau kalimat tanda ada salah struktur kata atau kalimatnya. Hal ini diharapkan produk final aplikasi "SAPA" dapat digunakan dalam membantu mahasiswa tunarungu, tunanetra, non-disabilitas dan dosen pengampu mata kuliah dalam perkuliahan.

\section{HASIL DAN PEMBAHASAN}

Pada dasarnya aplikasi SAPA memberikan fasilitas yang dapat digunakan untuk komunikasi antara beberapa pihak dengan menggunakan metode tertentu yang dapat digambarkan sebagai berikut:

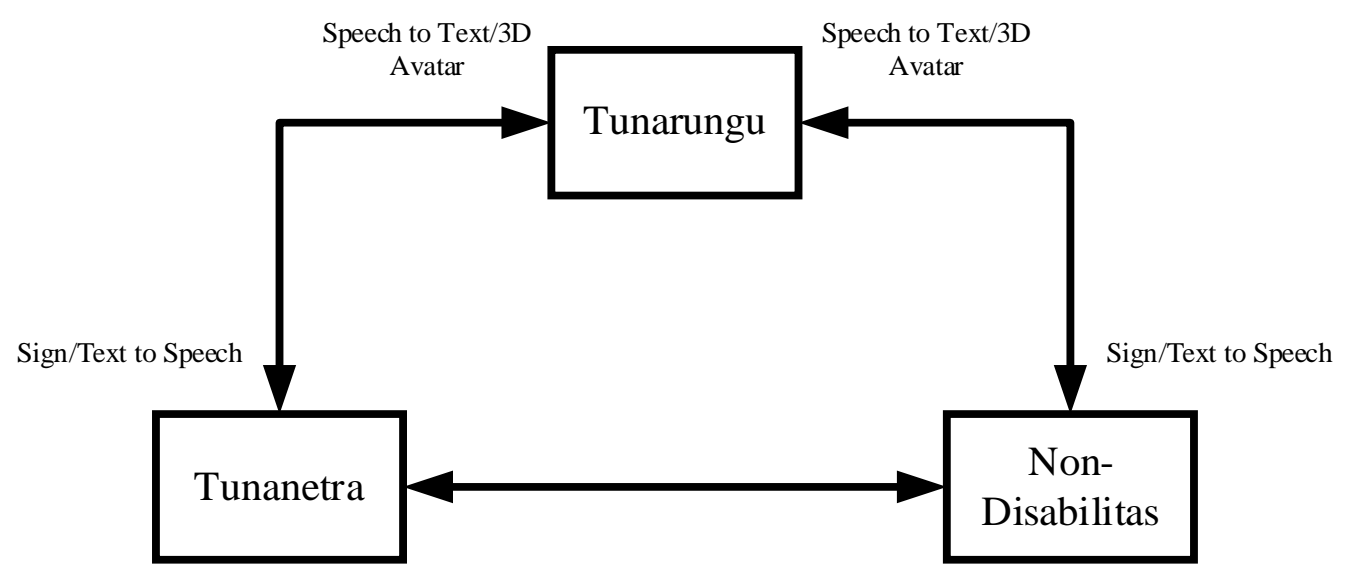

Gambar 1: Metode Komunikasi dengan SAPA

SAPA memberikan fasilitas bagi tunarungu untuk mengubah teks atau bahasa isyarat menjadi suara Ketika berkomunikasi dengan tunanetra atau non-disabilitas. Bagi tunanetra, SAPA mengubah suara menjadi teks atau bahasa isyarat ketika berkomunikasi dengan tunarungu. Tampilan aplikasi yang akan dibuat lebih detail, sebagai berikut; 

Anggrellangi

DOI: https://doi.org/10.31004/basicedu.v6i1.1931
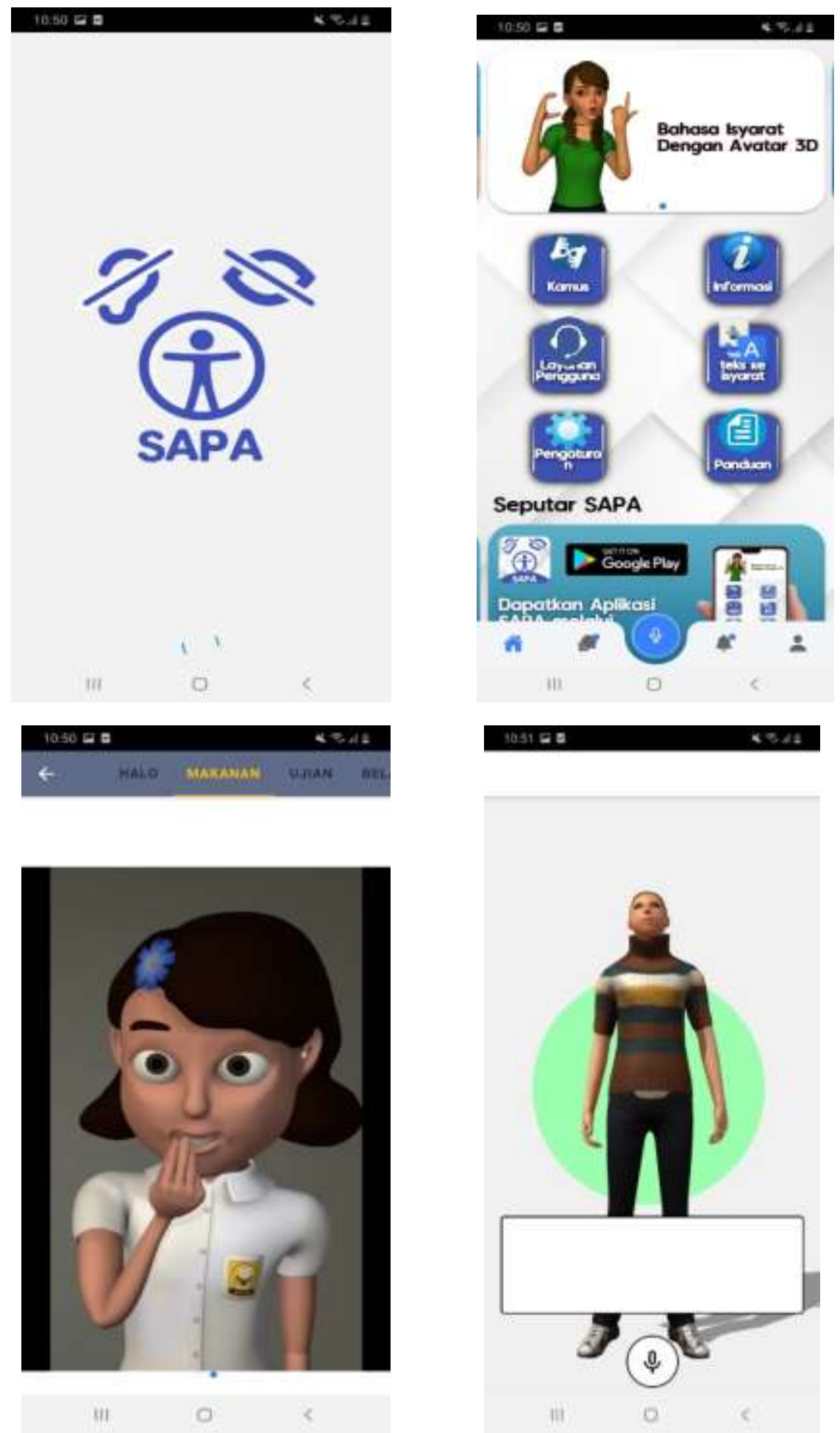

Gambar 2: Tampilan aplikasi "SAPA"

Hasil penerapan aplikasi "SAPA" dalam perkuliahan didasarkan pada pengujian dalam perkuliahan sangat efektif memudahkan mahasiswa tunarungu, tunantera, non-disabilitas, dan dosen dalam berkomunikasi. Hasil pengujian skala terbatas dapat dilihat lebih jelas pada analisis SPSS berikut: 
Tabel 1: Output Paired Samples Test

\begin{tabular}{|c|c|c|c|c|c|c|c|c|}
\hline \multicolumn{9}{|c|}{ Paired Samples Test } \\
\hline & \multicolumn{5}{|c|}{ Paired Differences } & $\mathrm{t}$ & df & $\begin{array}{l}\text { Sig. (2- } \\
\text { tailed) }\end{array}$ \\
\hline & \multirow[b]{2}{*}{ Mean } & \multirow{2}{*}{$\begin{array}{c}\text { Std. } \\
\text { Deviation } \\
\end{array}$} & \multirow{2}{*}{$\begin{array}{c}\text { Std. Error } \\
\text { Mean }\end{array}$} & \multicolumn{2}{|c|}{$\begin{array}{l}95 \% \text { Confidence } \\
\text { Interval of the } \\
\text { Difference }\end{array}$} & & & \\
\hline & & & & Lower & Upper & & & \\
\hline $\begin{array}{ll}\text { Pair } 1 & \text { Pre_test - } \\
& \text { Post_test }\end{array}$ & -16.591 & 4.194 & .894 & -18.450 & -14.732 & -18.556 & 21 & .000 \\
\hline
\end{tabular}

Berdasarkan hasil analisis tabel 1 yang berisi ouput Paired Samples Test di atas menunjukkan nilai Sig.(2-tailed) adalah sebesar $0.000<0.05$, maka $\mathrm{H}_{0}$ ditolak dan Ha diterima. Dapat ditarik kesimpulan bahwa, ada perbedaan rata - rata antara komunikasi mahasiswa pada saat sebelum dan sesudah menggunakan aplikasi "SAPA" yang artinya ada pengaruh pada penggunaan aplikasi "SAPA" untuk mengatasi masalah komunikasi mahasiswa tunarungu, tunanetra, non-disabilitas, dan dosen pengampu mata kuliah, sehingga tercipta komunikasi yang efektif dalam perkuliahan.

Kendala yang muncul pada penerapan aplikasi "SAPA" saat penerapan di kelas banyak suara - suara yang menggangu proses perkuliahan sehingga suara dosen atau teman yang seharusnya diterjemahkan terganggu oleh suara bising dari luar. Hal ini mengakibatkan terkendala dalam menerjemahkan kata - kata yang diucapkan oleh dosen dan temannya. Aplikasi "SAPA" masih butuh pengembangan lebih untuk menginput kata - kata dalam perkuliahan yang lebih banyak. Bahasa Isyarat dipergunakan dalam kehidupan berkomunikasi sehari-hari sesama mahasiswa tunarungu dengan tunanetra, non-disabilitas, dan dosen pengampu mata kuliah (Pradikja et al., 2018). Salah satu kesulitan adalah bagaimana kaum tunarungu dapat menginformasikan bahasa isyarat yang digunakan dan dapat dipahami oleh orang yang bisa mendengar sehingga penderita tunarungu dapat berkomunikasi, berinteraksi, bergaul, berteman, dan terjadi dialog dalam pergaulan sehari-hari, sehingga memerlukan pengembangan teknologi asistif seperti aplikasi yang dikembangkan dalam penelitian ini. Dengan terciptanya aplikasi pembelajaran bahasa isyarat berbasis android ini, memiliki manfaat untuk memudahkan pengguna dalam berkomunikasi (Hikmalansya, 2016).

\section{KESIMPULAN}

Pengembangan teknologi asistif ini sebagai bentuk mewujudkan membantu para mahasiswa penyandang disabilitas tunarungu diharapkan dapat terbantu untuk melakukan aktifitas sehari-hari. Alat bantu berupa aplikasi SAPA menggunakan model avatar 3D dalam merepresentasikan bahasa isyarat dan menggunakan algoritma cerdas speech recognition yang dapat mengolah bentuk suara menjadi bentuk lain. Aplikasi SAPA didesain dengan simple dan user-friendly, sehingga memberikan pengoperasian yang lebih mudah dan tepat guna. Penggunaan aplikasi SAPA membantu meningkatkan efektifitas komunikasi antara tunarungu dan tunanetra, serta kepada masyarakat umum. Selain itu dengan adanya aplikasi SAPA, diharapkan mampu memberikan komunikasi yang jelas dan tepat, sehingga mampu mengurangi kesalahan pemahaman atau miskonsepsi. Dengan teknologi asisitif ini dapat memberikan efek yang siginifikan pada interaksi sosial anatara tunarungu dan tunantera. 

Anggrellangi

DOI: https://doi.org/10.31004/basicedu.v6i1.1931

\section{UCAPAN TERIMA KASIH}

Terima kasih kepada Direktorat Jenderal Pendidikan Tinggi Kementerian Pendidikan, Kebudayaan, Riset, dan Teknologi yang telah memberikan Bantuan Dana Teknologi Asistif dalam Pembelajaran di Perguruan Tinggi 2021 dan Universitas Sebelas Maret yang telah memberikan bantuan dalam proses penyusunan aplikasi "SAPA".

\section{DAFTAR PUSTAKA}

Abdallah, E. E., \& Fayyoumi, E. 2016. Assistive Technology For Deaf People Based On Android Platform. Procedia Computer Science, 94(Fnc), 295-301.

Alnfiai, M., \& Sampali, S. 2017. Social And Communication Apps For The Deaf And Hearing Impaired. 2017 International Conference On Computer And Applications, Icca 2017, September, 120-126.

Bishop, J. M., Taylor, L., \& Froy, F. 2000. Computer-Mediated Communication Use By The Deaf And HardOf-Hearing. Kybernetes, 29(9-10), 1078-1086.

Bitman, N., \& John, N. A. 2019. Deaf And Hard Of Hearing Smartphone Users: Intersectionality And The Penetration Of Ableist Communication Norms. Journal Of Computer-Mediated Communication, 24(2), $56-72$.

Borg, W.R And Gall, M.D. 2003. Educational Research: An Introduction 4th Edition. London: Longman Inc.

Buvaneswari, B., Hemalatha, T., Kalaivani, G., Pavithra, P., \& Preethisree, A. R. 2020. Communication Among Blind, Deaf And Dumb People. International Journal Of Advanced Engineering, Management And Science, 6(4), 173-176.

Caporusso, N., Trizio, M., \& Perrone, G. 2014. Pervasive Assistive Technology For The Deaf-Blind Need, Emergency And Assistance Through The Sense Of Touch (Issue November).

Chee, K. N., Ibrahim, N. H., \& Yahaya, N. 2016. Designing Mobile Learning Communication Aid As An Android App. July 2019.

Destiny, I., Guo, Z., Turner, T. L., Defence, A., Academy, F., Donovan, L. A., Macintyre, P. D., Judge, T. A., Klinger, R., Simon, L. S., Yang, I. W. F., Hecht, M. L., Daud, M. F., Syakir, A., Salleh, S., Latif, A., Njoroge, B., Oyeniran, S., Sayo, J., ... Devito, J. A. 2017. Computer Mediated Communication For Effective And Efficient Organization Service Delivery Amid Covid-19 Pandemic. Social And Personality Psychology Compass, 21(4), 213-226.

Durkin, K., Conti-Ramsden, G., \& Walker, A. J. 2010. Computer-Mediated Communication In Adolescents With And Without A History Of Specific Language Impairment (Sli). Computers In Human Behavior, 26(2), 176-185.

Eden, S., \& Heiman, T. 2011. Computer Mediated Communication: Social Support For Students With And Without Learning Disabilities. Educational Technology And Society, 14(2), 89-97.

Ehn, M., Anderzén-Carlsson, A., Möller, C., \& Wahlqvist, M. 2019. Life Strategies Of People With Deafblindness Due To Usher Syndrome Type 2a - A Qualitative Study. International Journal Of Qualitative Studies On Health And Well-Being, 14(1).

Fuad Akhsan, M. R. R. 2020. Motif Komunikasi Bermedia Pada Penyandang Disabilitas (Studi Pada Penyandang Disabilitas Netra Yang Menggunakan Instagram) Communication. E-Proceeding Of Management , 7(2), 4533-4546.

Gambo, S., \& Özad, B. O. 2020. The Demographics Of Computer-Mediated Communication: A Review Of Social Media Demographic Trends Among Social Networking Site Giants. Computers In Human Behavior Reports, 2(May), 100016. 

Anggrellangi

DOI: https://doi.org/10.31004/basicedu.v6i1.1931

Garberoglio, C. Lou, Dickson, D., Cawthon, S., \& Bond, M. (2015). Bridging The Communication Divide: Cmc And Deaf Individuals' Literacy Skills. Language, Learning And Technology, 19(2), 118-133.

Hersh, M. 2013. Deafblind People, Communication, Independence, And Isolation. Journal Of Deaf Studies And Deaf Education, 18(4), 446-463.

Hikmalansya, J. K. 2016. Aplikasi Pembelajaran Bahasa Isyarat Berbasis Android. Inform: Jurnal Ilmiah Bidang Teknologi Informasi Dan Komunikasi, 1(2), 118-124.

Landicho, J. A. 2016. Voisee Communicator: An Android Mobile Application For Hearing-Impaired And Blind Communications. International Journal Of Interactive Mobile Technologies, 10(4), 26-31.

Maciver, D., Rutherford, M., Arakelyan, S., Kramer, J. M., Richmond, J., Todorova, L., Romero-Ayuso, D., Nakamura-Thomas, H., Velden, M. Ten, Finlayson, I., O’hare, A., \& Forsyth, K. 2019. Participation Of Children With Disabilities In School: A Realist Systematic Review Of Psychosocial And Environmental Factors. Plos One, 14(1), 1-22.

Monteiro, I. T., Da Silva Alves, A., \& De Souza, C. S. 2013. Using Mediated Communication To Teach Vocational Concepts To Deaf Users. Lecture Notes In Computer Science (Including Subseries Lecture Notes In Artificial Intelligence And Lecture Notes In Bioinformatics), 8011 Lncs(Part 3), 213-222.

Nuraeni Zaenudin, H. 2017. Computer Mediated Communication In E-Marketing Of Indonesia University Education. 84(Iconeg 2016), 5-9.

Okonji, P. E. 2018. Use Of Computer Assistive Technologies By Older People With Sight Impairment: Perceived State Of Access And Considerations For Adoption. British Journal Of Visual Impairment, $36(2), 128-142$.

Pradikja H, M., Tolle, H., \& Candra Brata, K. 2018. Pengembangan Aplikasi Pembelajaran Bahasa Isyarat Berbasis Android Tablet. Jurnal Pengembangan Teknologi Informasi Dan Ilmu Komputer (J-Ptiik), 2(8), 2548-2964.

Ramadhana, M. R., \& Yusanto, F. 2020. Computer-Mediated Communication And Family Communication Among Deaf Teenager. Ijds Indonesian Journal Of Disability Studies, 7(2), 230-238.

Skilton, A., Boswell, E., Prince, K., Francome-Wood, P., \& Moosajee, M. 2018. Overcoming Barriers To The Involvement Of Deafblind People In Conversations About Research: Recommendations From Individuals With Usher Syndrome. Research Involvement And Engagement, 4(1), 1-12.

Tukimin, S., Handayani, D., Alimin, Z., \& Somad, P. 2019. Indonesia Deaf And Blind Communication System (Idbc-System). Education And Information Technologies, 24(3), 2017-2033. 